\title{
Metabolic characterization of colorectal cancer cells harbouring different KRAS mutations in codon 12,13, 61 and 146 using human SW48 isogenic cell lines
}

\author{
Dorna Varshavi ${ }^{1} \cdot$ Dorsa Varshavi $^{1} \cdot$ Nicola McCarthy ${ }^{2}$ [D $\cdot$ Kirill Veselkov $^{3} \cdot$ Hector C. Keun $^{4} \cdot$ Jeremy R. Everett $^{1}$ (D)
}

Received: 16 December 2019 / Accepted: 2 April 2020 / Published online: 16 April 2020

(c) The Author(s) 2020

\begin{abstract}
Introduction Kirsten Rat Sarcoma Viral Oncogene Homolog (KRAS) mutations occur in approximately one-third of colorectal (CRC) tumours and have been associated with poor prognosis and resistance to some therapeutics. In addition to the well-documented pro-tumorigenic role of mutant Ras alleles, there is some evidence suggesting that not all KRAS mutations are equal and the position and type of amino acid substitutions regulate biochemical activity and transforming capacity of KRAS mutations.

Objectives To investigate the metabolic signatures associated with different $K R A S$ mutations in codons 12, 13, 61 and 146 and to determine what metabolic pathways are affected by different KRAS mutations.

Methods We applied an NMR-based metabonomics approach to compare the metabolic profiles of the intracellular extracts and the extracellular media from isogenic human SW48 CRC cell lines with different KRAS mutations in codons 12 (G12D, G12A, G12C, G12S, G12R, G12V), 13 (G13D), 61 (Q61H) and 146 (A146T) with their wild-type counterpart. We used false discovery rate (FDR)-corrected analysis of variance (ANOVA) to determine metabolites that were statistically significantly different in concentration between the different mutants.

Results CRC cells carrying distinct KRAS mutations exhibited differential metabolic remodelling, including differences in glycolysis, glutamine utilization and in amino acid, nucleotide and hexosamine metabolism.

Conclusions Metabolic differences among different KRAS mutations might play a role in their different responses to anticancer treatments and hence could be exploited as novel metabolic vulnerabilities to develop more effective therapies against oncogenic KRAS.
\end{abstract}

Keywords KRAS $\cdot$ Mutations $\cdot$ Colorectal cancer $\cdot$ Metabonomics $\cdot$ Metabolomics $\cdot$ Metabolic profiling $\cdot$ NMR

\section{Introduction}

Electronic supplementary material The online version of this article (https://doi.org/10.1007/s11306-020-01674-2) contains supplementary material, which is available to authorized users.

Jeremy R. Everett

j.r.everett@greenwich.ac.uk

1 Medway Metabonomics Research Group, University of Greenwich, Chatham Maritime, Kent ME4 4TB, UK

2 Horizon Discovery Ltd., Cambridge Research Park, 8100 Beach Dr, Waterbeach, Cambridge CB25 9TL, UK

3 Department of Surgery and Cancer, Faculty of Medicine, Imperial College, London SW7 2AZ, UK

4 Department of Surgery and Cancer, Imperial College London, Hammersmith Hospital Campus, London W12 ONN, UK
KRAS is a gene that has the potential to cause cancer when it is mutated i.e. it is an oncogene. Point mutations in the $K R A S$ gene are present in approximately $35-45 \%$ of colorectal cancers (Dinu et al. 2014; Tan and Du 2012), and serve as a negative predictive factor of response to anti-EGFR therapy (Lievre et al. 2006). These mutations lead to the loss of intrinsic GTPase activity and therefore to increased proliferation and resistance to apoptosis (Jia et al. 2017). The majority of KRAS mutations occur in codons 12 and 13, while other mutations, such as those in codons 61 and 146 are less common (Guarnaccia et al. 2018; Margonis et al. 2015; Stolze et al. 2015). The most common point mutations in codon 12 and 13 are codon 12 Gly $\rightarrow$ Asp (G12D), codon 12 Gly $\rightarrow$ Val (G12V), and codon 13 Gly $\rightarrow$ Asp (G13D) substitutions (Seekhuntod 
et al. 2016). It is well known that not all KRAS mutations are equivalent and the position and type of amino acid substitutions regulate both the biochemical activity and transforming capacity of $K R A S$ mutations (Brunelli et al. 2014). For example, it has been reported that mutations of $K R A S$ at codon 12 have greater transforming ability than at codon 13 and are linked with a more aggressive cancer phenotype, although, patients with codon 13 mutations exhibit a markedly worse prognosis (Yokota 2012). Moreover, it has been suggested that different KRAS mutations display different responses to treatments. For instance, patients with G13D mutations have been shown to respond better to anti-EGFR therapy compared to patients with other KRAS mutations (Kishiki et al. 2014; Stolze et al. 2015; Tural et al. 2013).

Oncogenic KRAS has been shown to promote the decoupling of glycolysis and TCA metabolism, with glutamine fuelling the TCA cycle as an alternative source of carbon (Son et al. 2013). These findings support the notion that oncogenic KRAS plays a key role in the metabolic reprogramming of cancer cells (Vizan et al. 2005; Ying et al. 2012). Moran et al. found that KRAS mutation was associated with increased dependency on folate metabolism in non-small cell lung cancer cells (Moran et al. 2014). A panel of KRAS mutants in isogenic SW48 colon cancer cell lines exhibited a unique signalling network signature and proteome expression profile (Hammond et al. 2015). In addition, Kerr et al. demonstrated that homozygous KRAS G12D/ G12D cells had a glycolytic switch and increased channelling of glucose-derived metabolites into the TCA cycle and glutathione biosynthesis (Kerr et al. 2016). However, in spite of all this work, the overall metabolic dysregulation driven by different KRAS mutations in colorectal cancer is still not clear.

Since metabolic reprogramming is a hallmark of cancer and differential metabolic reprogramming is important in the development and selection of effective therapies, we applied an exploratory, NMR-based metabonomics approach to characterize the metabolic pathways affected in isogenic SW48 cells harbouring different $K R A S$ mutations at codons 12,13 , 61 and 146. Not only will this work help explain why different $K R A S$ mutations give rise to different cancer metabolism and phenotypic outcomes but also, the identification of metabolic pathways associated with specific KRAS mutations may be of use in the design of more effective targeted therapies for colorectal cancer in the future.

\section{Materials and methods}

\subsection{Cell culture}

Isogenic SW48 colorectal carcinoma cell lines were sourced from Horizon Discovery Ltd (Cambridge, UK). All of these cell lines were generated using a recombinant Adeno-Associated Virus (rAAV)-based gene editing platform according to published methods (Arena et al. 2007; Vartanian et al. 2013). All cell lines were cultured in McCoy's 5A medium (Gibco, Life Technologies, UK), supplemented with $10 \%$ foetal bovine serum (FBS) (Gibco, UK). Cells were grown in $150 \mathrm{~cm}^{2}$ cell culture flasks (Corning, UK), incubated at $37{ }^{\circ} \mathrm{C}$ in a humidified atmosphere containing $5 \% \mathrm{CO}_{2}$ and passaged routinely until they reached approximately $80-90 \%$ confluence. All experiments were performed in five biological replicates.

\subsection{Cell harvesting method}

The medium was removed from the attached cells in a $\mathrm{T} 150 \mathrm{~cm}^{2}$ flask and the cells were washed once with $20 \mathrm{~mL}$ phosphate buffered saline (PBS, pH 7.0-7.3, $\mathrm{CaCl}_{2^{-}}$and $\mathrm{MgCl}_{2}$-free, Gibco, Life Technologies, UK) at room temperature to remove residual serum. $3 \mathrm{ml} 0.05 \%$ Trypsin-EDTA (Gibco, Life Technologies, UK) was added to the flasks and these were incubated at $37^{\circ} \mathrm{C}$ for $3 \mathrm{~min}$. Once the cells had detached (checked using a phase contrast inverted microscope) $10 \mathrm{~mL}$ of complete medium was added to dilute the trypsin. The media containing the detached cells was transferred into a $50 \mathrm{~mL}$ conical tube (Fisher Scientific, UK). Cells collected from different flasks were mixed into one tube and then $300 \mu \mathrm{L}$ of cell suspension was removed for accurate cell counting using a Nucleocounter (Chemometec, Denmark). The cell suspension was centrifuged at $1400 \mathrm{rpm}$ for $5 \mathrm{~min}$ at room temperature. After removing the media, the cell pellet was suspended in Opti-MEM media (Gibco, Life Technologies, UK) and aliquots $(1 \mathrm{~mL})$ containing $2 \times 10^{7}$ SW48 cells were added in $5 \mathrm{~T} 75 \mathrm{~cm}^{2}$ low adherence flasks (Corning, UK) containing $9 \mathrm{~mL}$ of Opti-MEM medium. After incubation at $37{ }^{\circ} \mathrm{C}$ for $6 \mathrm{~h}$, the cells from each flask were harvested and transferred into a $15 \mathrm{~mL} \mathrm{Fal-}$ con tube (Fisher Scientific, UK). The cell suspension was centrifuged at $1400 \mathrm{rpm}$ for $5 \mathrm{~min}$ at $4{ }^{\circ} \mathrm{C}$, the Opti-MEM media was removed and the cell pellet was washed once with $10 \mathrm{~mL}$ ice cold PBS to remove extracellular metabolites. After removing PBS by centrifugation (1400 rpm and $4{ }^{\circ} \mathrm{C}$ for $5 \mathrm{~min}$ ), the cell pellets were immediately frozen in liquid nitrogen and stored at $-80^{\circ} \mathrm{C}$. The Opti-MEM media removed from SW48 cells was also snap frozen in liquid nitrogen and stored at $-80{ }^{\circ} \mathrm{C}$.

\subsection{Metabolite extraction of SW48 cell lines}

Cells were extracted in $1000 \mu \mathrm{L}$ chilled $\mathrm{MeOH} / \mathrm{H}_{2} \mathrm{O}$ $\left(-20{ }^{\circ} \mathrm{C}, 80 / 20(\mathrm{v} / \mathrm{v})\right)$ for $30 \mathrm{~s}$ at $15 \mathrm{~Hz}$ using $2 \mathrm{~mL}$ CK28-R reinforced ceramic homogenising tubes and a TissueLyser II (QIAGEN, UK). The samples were centrifuged at $4{ }^{\circ} \mathrm{C}$ and $7000 \times g$ for $5 \mathrm{~min}$ and the supernatant was collected 
into a new Eppendorf tube. The pellet was re-extracted once with $1000 \mu \mathrm{L}$ cold methanol/water $\left(-20^{\circ} \mathrm{C}, 80 / 20(\mathrm{v} / \mathrm{v})\right)$ to produce $2 \mathrm{~mL}$ of extract. The supernatants were combined, dried under a gentle flow of $\mathrm{N}_{2}$ gas (Labconco RapidVap evaporator) and stored at $-80^{\circ}$ until NMR analysis.

\subsection{Sample preparation for NMR analysis}

Cell extracts were resuspended by vortexing in $180 \mu \mathrm{L}$ phosphate buffer $\left(81 / 19(\mathrm{v} / \mathrm{v})\right.$ mixture of $0.1 \mathrm{M} \mathrm{K}_{2} \mathrm{HPO}_{4}$ and $\mathrm{NaH}_{2} \mathrm{PO}_{4}$ in $100 \%{ }^{2} \mathrm{H}_{2} \mathrm{O}$ with $0.1 \mathrm{mM} 3$-(trimethylsilyl)propionic-2,2,3,3-d4 acid sodium salt (TSP), $\mathrm{pH}$ 7.4). The buffered samples were then centrifuged at 10,000 rpm for $1 \mathrm{~min}$ at $4{ }^{\circ} \mathrm{C}$ to remove any suspended particles. After centrifugation, the supernatant was transferred into $3 \mathrm{~mm}$ diameter NMR tubes (SampleJet Tube $3.0 \times 103.5 \mathrm{~mm}$, Bruker Spectrospin; Z112272) using an electronic syringe (SGE-Analytical Science, UK). In addition, four SW48 $K R A S^{\mathrm{G} 13 \mathrm{D} /+}$ extracts were pooled for analysis in $5 \mathrm{~mm}$ o.d. NMR tubes (NORELL, 508-UP-7), in order to provide greater sensitivity for two-dimensional NMR experiments for metabolite identification.

\subsection{Cell culture medium sample preparation for NMR analysis}

$500 \mu \mathrm{L}$ of Opti-MEM cell medium collected from SW48 cell lines was mixed with $250 \mathrm{ul}$ of phosphate buffer $(81: 19(\mathrm{v} / \mathrm{v})$ mixture of $0.6 \mathrm{M} \mathrm{K}_{2} \mathrm{HPO} 4$ and $\mathrm{NaH}_{2} \mathrm{PO}_{4}$ in $100 \%{ }^{2} \mathrm{H}_{2} \mathrm{O}$, pH 7.4) containing TSP $(0.5 \mathrm{mM}$, Sigma-Aldrich) and sodium azide ( $9 \mathrm{mM}$, Sigma-Aldrich). $600 \mu \mathrm{L}$ samples were then transferred into $5 \mathrm{~mm}$ diameter NMR tubes (Norell, S-1.7500-1) and ${ }^{1} \mathrm{H}$ NMR spectra of cell culture media acquired.

\section{$2.6{ }^{1} \mathrm{H}$ NMR spectroscopy}

${ }^{1} \mathrm{H}$ NMR spectra of the metabolites were acquired on a $600 \mathrm{MHz}$ Bruker Avance spectrometer (Bruker BioSpin $\mathrm{GmbH}$, Rheinstetten, Germany) operating at a temperature of $300.0 \mathrm{~K}$. Standard 1D ${ }^{1} \mathrm{H}$ NMR spectra were acquired with a 1D NOESY pulse sequence (RD- $90^{\circ}-t 1-90^{\circ}-t \mathrm{~m}-90^{\circ}$ acquire, pulse sequence noesygppr1d) with water suppression applied during the relaxation delay (RD) of $4 \mathrm{~s}$ and mixing time (tm) of $10 \mathrm{~ms} .128$ transients for SW48 culture medium and 256 transients for SW48 cell extracts were collected into 65,536 data points with a spectral width of $20 \mathrm{ppm}$.

\subsection{Two-dimensional NMR analysis of cell extracts}

Two-dimensional NMR experiments were performed on representative samples to ensure the unambiguous assignment of the identities of the metabolites. The detailed parameters for the acquisition of the 2D NMR spectra of SW48 KRAS $S^{\mathrm{G} 13 \mathrm{D} /+}$ and media of SW48 KRAS $S^{+/+}$are provided in Supplementary Tables 1 and 2.

\subsection{NMR data treatment}

Prior to Fourier transformation, each free induction decay (FID) was multiplied by an exponential function equivalent to a $0.3 \mathrm{~Hz}$ line broadening, in order to improve the signalto-noise ratio. The resulting spectra were phase corrected, baseline corrected and referenced relative to the chemical shift of the methyl protons of TSP $(0.0 \mathrm{ppm})$ using TOPSPIN 3.2 (Bruker Biospin, UK). The NMR spectra were imported into Matlab (R2010 b, Mathworks) and analysed using in-house Matlab routines written by the team of Dr $\mathrm{K}$. Veselkov. The regions of the spectra upfield of $0.8 \mathrm{ppm}$, downfield of $10 \mathrm{ppm}$ and the water region $(\delta 4.7-5.2)$ were excluded to eliminate the effects of variable water saturation and background noise. All NMR spectra were normalised according to the "Probabilistic Quotient Normalization (Dieterle et al. 2006)" method in order to compensate for variations in the overall concentrations of the samples. In order to correct chemical shift variations between the different samples, due to minor changes in $\mathrm{pH}$, ionic strength and solute composition, NMR spectra were aligned using recursive segment-wise peak alignment (RSPA) method. After alignment, all NMR data were log-transformed to convert multiplicative noise into additive noise (Veselkov et al. 2011).

\subsection{Pattern recognition and multivariate data analysis}

Pattern recognition analyses were performed as described previously (Varshavi et al. 2018). Initially, NMR spectral data were subjected to principal component analysis (PCA) to visualize the general structure of each data set and to identify sub-groups and any potential outliers within the data. Subsequently, a supervised multivariate analysis known as maximum margin criterion (MMC) was applied to simultaneously maximize the inter-group differences i.e. cell genotypes, whilst minimising within group differences i.e. biological replicates (Veselkov et al. 2014). The validity of the MMC models was checked by performing a "leave-one-out" cross-validation using the quadratic as a classifier. One-way analysis of variance (ANOVA) with a false discovery rate (FDR) of 0.1 i.e. $10 \%$ to account for multiple hypothesis testing (Benjamini 2010) was employed to determine metabolites that individually (irrespective of other metabolites) have a different abundance between groups. The FDR approach was used in order to avoid the well-known problems that can 
arise due to multiple hypothesis testing in high dimensional datasets (Benjamini 2010; Han et al. 2009).

\subsection{Metabolite identification}

Statistically significantly discriminating metabolites were identified by (i) comparison with reference spectra from the Human Metabolome Database (HMDB https://www. hmdb.ca/) (Wishart et al. 2007) and the Biological Magnetic Resonance Data Bank (BMRB, https://www.bmrb.wisc.edu/ metabolomics/); (ii) analysis of previously published data; and (iii) the interpretation of a series of two-dimensional (2D) spectra such as 2D ${ }^{1} \mathrm{H}$ COSY, J-resolved, HSQC and HMBC, using published methods(Dona et al. 2016; Everett 2015).

\section{Results}

\subsection{Intracellular metabolic profiling of isogenic, human colorectal cancer cells harbouring different KRAS mutations in codon 12 and 13}

An unsupervised PCA scores plot of all biological replicates of all SW48 cell lines expressing either wild-type or mutant KRAS in either codon 12 or 13 (Fig. 1) showed good clustering and separation of each mutant from $K R A S$
WT, with the most variability observed between G13D and the codon $12 K R A S$ mutants and the wild-type. These data indicate that each activating KRAS mutation generates a unique metabolic signature that is distinct from KRAS WT. Representative ${ }^{1} \mathrm{H}$ NMR spectra of three of these isogenic cell lines are shown in Supplementary Fig. 1.

The supervised dimension reduction technique, maximum margin criterion (MMC) (Veselkov et al. 2014) showed somewhat improved class separation (Supplementary Fig. 2). Correct classification rates of $100 \%$ were observed for all models. Leave-one-out cross-validation with the quadratic as a classifier was applied (Supplementary Fig. 3).

One-way ANOVA with a false discovery rate (FDR) of $10 \%$, was used to determine the statistically significantly different metabolites between the KRAS mutant cells and their KRAS wild type isogenic cell lines (Fig. 2 and Supplementary Figs. 4-9). Table 1 lists the statistically significant discriminating metabolites and their associated HMDB identification numbers. G12V displayed the most marked metabolic remodelling. All metabolites are identified at MSI Level 2 (Sumner et al. 2007) and confidently identified by MICE methodology (Everett 2015). Comparison of relative fold-changes in the significantly altered metabolites in each KRAS mutant with their WT counterpart showed that KRAS mutations mostly reduced the amount of metabolites relative to WT (Table 2 and Supplementary Tables 3-8).
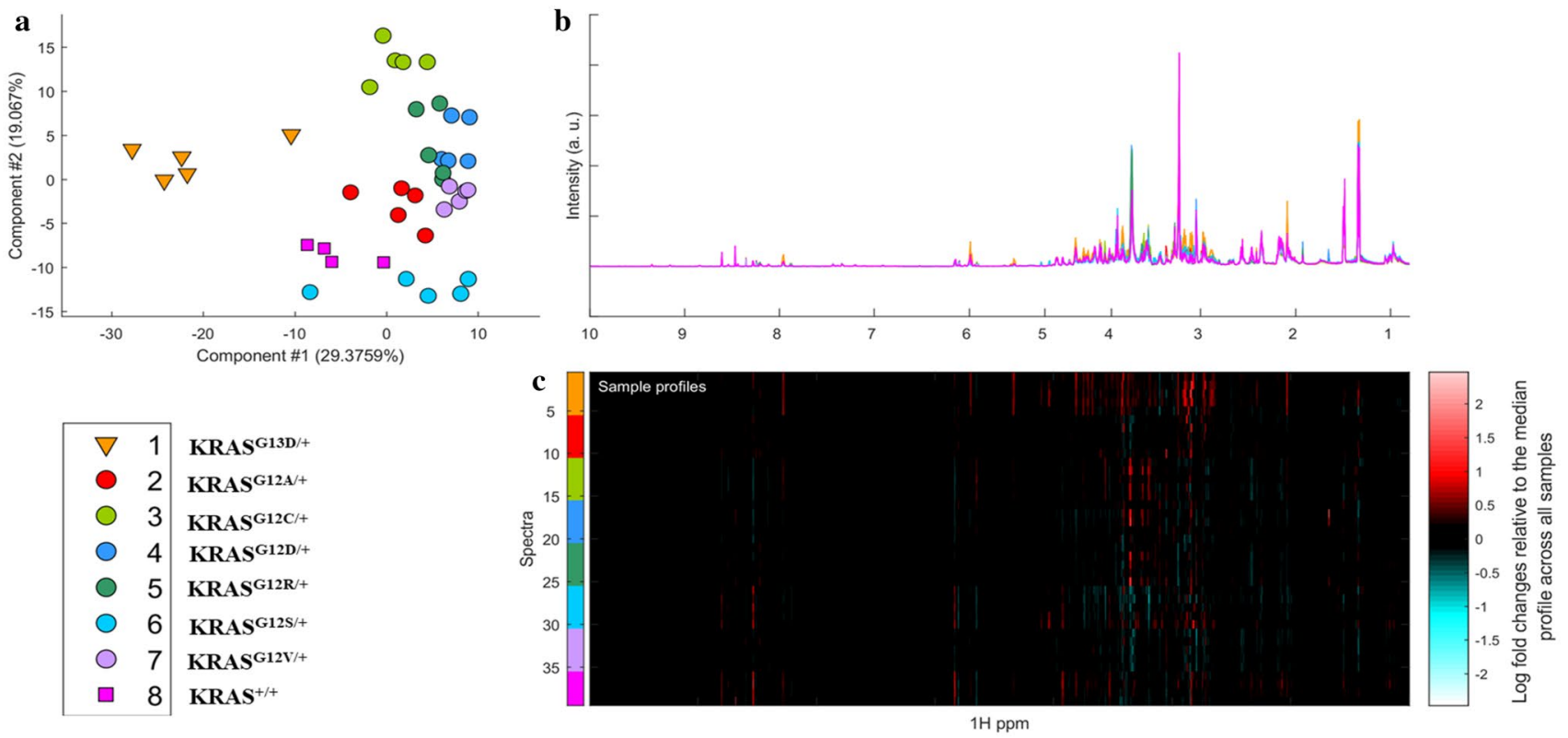

Fig. 1 a PCA scores plot of the $600 \mathrm{MHz}{ }^{1} \mathrm{H}$ NMR spectra from extracts of SW48 cells with KRAS mutations in codons 12 and 13 and their wild type counterpart, $\mathrm{KRAS}^{+/+}$; b superimposed NMR spectra of SW48 cells, with the same colour coding as in the PCA plot, part (a); c the corresponding heat map display of the $600 \mathrm{MHz}{ }^{1} \mathrm{H}$ NMR spectra of SW48 cell lines from 0.8 to $10.0 \mathrm{ppm}$. Red and blue elements in the spectra indicate NMR signals that are more intense, or less intense, respectively, than the median signal intensity for all the samples 

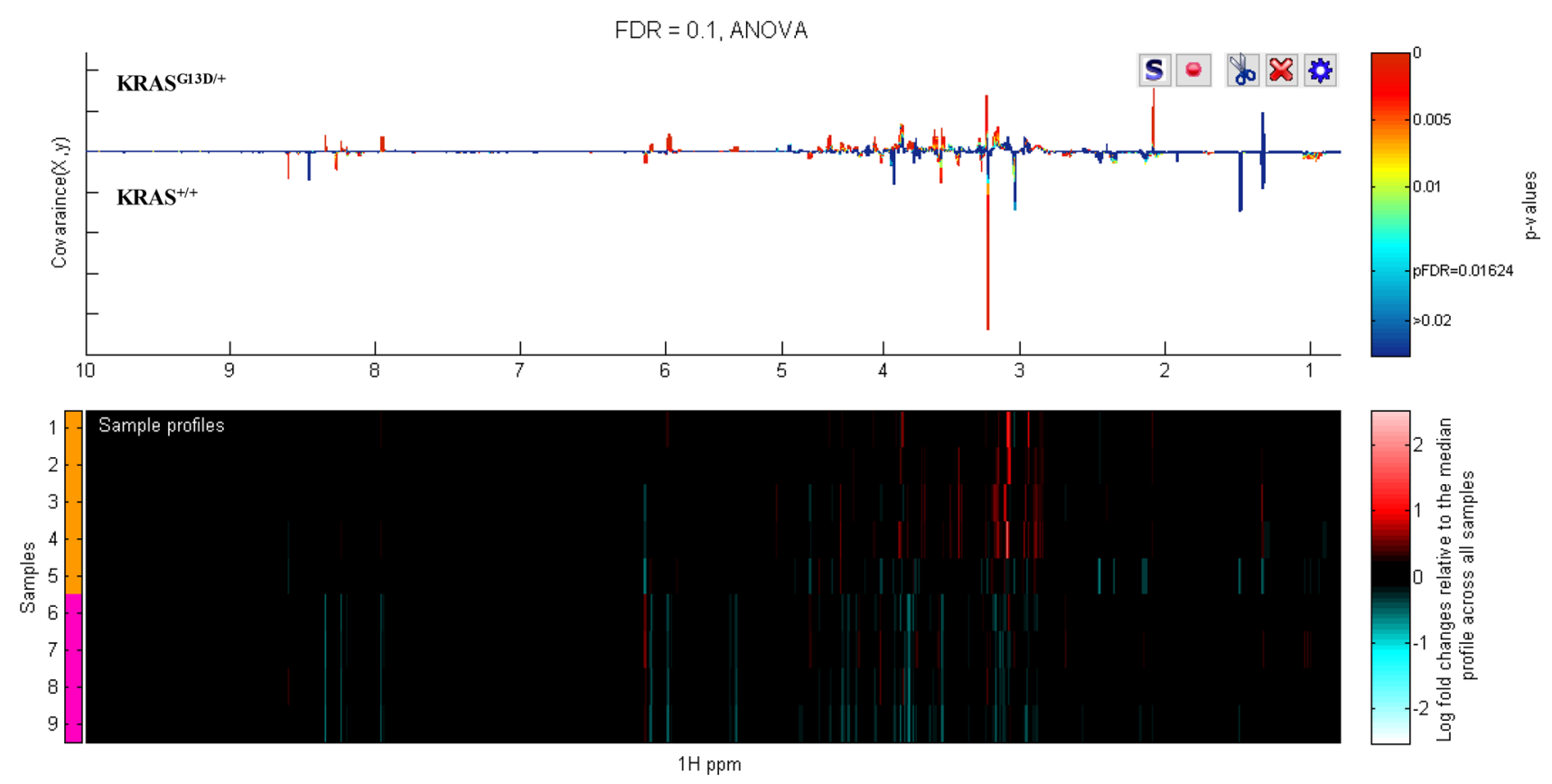

Fig. 2 At bottom a 'heat map display of the $600 \mathrm{MHz}{ }^{1} \mathrm{H}$ NMR spectra of $K R A S^{\mathrm{G} 13 \mathrm{D} /+}$ (top 5 strips) vs the corresponding spectra of parental cell line $\left(K R A S^{+/+}\right)$(bottom 4 strips). Red and blue elements in the spectra indicate NMR signals that are more intense, or less intense, respectively, than the median signal intensity for all the samples. At top, the corresponding ANOVA plot, showing positive peaks

To further understand the biological significance of the metabolite changes in the KRAS mutant clones, we used enrichment analysis (EA) tools in MetaboAnalyst to link metabolites to metabolic pathways (Fig. 3 and Supplementary Figs. 10-12). In all seven KRAS mutant clones, protein biosynthesis, urea cycle, RNA transcription and ammonia recycling pathways were over-represented. The levels of amino acids involved in protein synthesis were mostly lower in the mutant KRAS clones compared to WT, with the exception of the greater amount of aspartate in the G12C, G12D and G12R clones (Supplementary Table 9). All G12 KRAS mutants showed a lower level of glutamine. In parallel, both G13 and G12 mutations (except for G12A, G12D and G12R, where there was no significant change) had a lower intracellular concentration of glutamate, indicating that most KRAS mutations used glutaminolysis to provide the energy for growing and proliferation. G12D and G12V mutants also had lower intracellular concentrations of NAD+, a vital coenzyme regulating several cellular metabolic pathways. Moreover, with the exception of KRAS G12C, all cell lines with mutations in codon 12 showed lower levels of UDP- $N$-acetylglucosamine and UDP- $N$-acetylgalactosamine, while KRAS G13D exhibited an increased level of UDP- $N$-acetylglucosamine for those metabolite signals that are more intense in $K R A S^{\mathrm{G} 13 \mathrm{D} /+}$, and negative peaks for those metabolite signals that are less intense. The signals are colour coded by the $\mathrm{p}$ value adjusted for an FDR of 0.1 . The FDR-adjusted $p$ value for statistically significant difference, $\mathrm{pFDR}$, is 0.016 in this case

and UDP- $N$-acetylgalactosamine compared to KRAS WT. All KRAS mutants with the exception of KRAS G12S showed lower levels of adenosine monophosphate (AMP) and higher levels of inosine and uridine compared to wild type. Furthermore, lower levels of UMP were observed in all KRAS mutants except for G12S, G12A and G12R. Analysis of intracellular metabolites in G12 KRAS mutations revealed decreased level of GPC in cell lines harbouring G12C, G12D, G12V and G12R mutations. Phosphocholine levels were reduced in cell lines with G12R mutation, while the levels of choline were increased in $\mathrm{G} 12 \mathrm{C}$ and G12R and decreased in G12V. G13D mutants exhibited significantly higher levels of GPC compared to WT. Choline levels were not found to be significantly different between G13D mutants and WT, while PCho levels were found to be lower in mutated cells. While some metabolites showed similar patterns of changes across the majority of KRAS mutants, others were unique for each KRAS mutation. For instance, the levels of taurine were reduced in cell lines with G13D and G12V mutations, whilst increased in cell lines harbouring G12D and G12R mutations. KRAS G13D and G12C also had higher intracellular concentrations of myo-inositol, while G12S exhibited reduced levels of myoinositol compared to WT. 
Table 1 Summary of the most significant metabolites differentiating between SW48 cells with KRAS mutations in codons 12 and 13 and their wild type counterpart

\begin{tabular}{|c|c|c|c|c|c|c|c|c|}
\hline Metabolite & $\begin{array}{l}{ }^{1} \mathrm{H} \text { NMR parameters: chemi- } \\
\text { cal shift in ppm (multiplicity, d } \\
\text { doublet, m multiplet, s singlet, t } \\
\text { triplet) }\end{array}$ & $\begin{array}{l}\text { G13D/+ } \\
\text { vs }+/+\end{array}$ & $\begin{array}{l}\text { G12S/+ } \\
\text { vs }+/+\end{array}$ & $\begin{array}{l}\text { G12A/+ } \\
\text { vs }+/+\end{array}$ & $\begin{array}{l}\text { G12C/+ } \\
\text { vs }+/+\end{array}$ & $\begin{array}{l}G 12 D /+ \\
\text { vs }+/+\end{array}$ & $\begin{array}{l}G 12 \mathrm{~V} /+ \\
\mathrm{vs}+/+\end{array}$ & $\begin{array}{l}G 12 R /+ \\
\text { vs }+/+\end{array}$ \\
\hline $\begin{array}{l}\text { Isoleucine } \\
\text { HMDB000172 }\end{array}$ & $0.943(\mathrm{t}), 1.01(\mathrm{~d}), 3.675(\mathrm{~d})$ & $\downarrow$ & - & $\downarrow$ & $\downarrow$ & $\downarrow$ & $\downarrow$ & - \\
\hline $\begin{array}{l}\text { Leucine } \\
\text { HMDB00687 }\end{array}$ & $\begin{array}{l}0.961(\mathrm{~d}), 0.972(\mathrm{~d}), 1.691(\mathrm{~m}) \\
1.720(\mathrm{~m}), 1.748(\mathrm{~m}), 3.737(\mathrm{dd})\end{array}$ & $\downarrow$ & - & $\downarrow$ & $\downarrow$ & $\downarrow$ & $\downarrow$ & - \\
\hline $\begin{array}{l}\text { Valine } \\
\text { HMDB0000883 }\end{array}$ & $0.996(d), 1.046(d), 3.615(d)$ & $\downarrow$ & - & $\downarrow$ & $\downarrow$ & $\downarrow$ & $\downarrow$ & - \\
\hline $\begin{array}{l}\text { Lactate } \\
\text { HMDB00190 }\end{array}$ & $1.331(\mathrm{~d}), 4.113(\mathrm{q})$ & - & - & - & - & $\downarrow$ & $\downarrow$ & - \\
\hline $\begin{array}{l}\text { Threonine } \\
\text { HMDB0000167 }\end{array}$ & $1.335(\mathrm{~d}), 3.591(\mathrm{~d})$ & - & & - & $\downarrow$ & $\downarrow$ & $\downarrow$ & - \\
\hline $\begin{array}{l}\text { Alanine } \\
\text { HMDB0000161 }\end{array}$ & $1.485(\mathrm{~d}), 3.787(\mathrm{q})$ & - & - & - & $\downarrow$ & - & $\downarrow$ & - \\
\hline $\begin{array}{l}\text { UDP- } N \text {-acetyl-glucosamine } \\
\text { HMDB00290 }\end{array}$ & $\begin{array}{l}2.084(\mathrm{~s}), 4.295(\mathrm{~m}), 4.367(\mathrm{~m}) \\
5.523(\mathrm{dd}), 5.975(\mathrm{~d}), 5.991(\mathrm{~d}) \\
7.958(\mathrm{~d})\end{array}$ & $\uparrow$ & $\downarrow$ & $\downarrow$ & - & $\downarrow$ & $\downarrow$ & $\downarrow$ \\
\hline $\begin{array}{l}\text { UDP- } N \text {-acetyl-galactosamine } \\
\text { HMDB0000304 }\end{array}$ & $\begin{array}{l}2.088(\mathrm{~s}), 3.770(\mathrm{~m}), 4.255(\mathrm{~m}) \\
5.556(\mathrm{dd}), 5.975(\mathrm{~d}), 5.990(\mathrm{~d})\end{array}$ & $\uparrow$ & $\downarrow$ & $\downarrow$ & - & $\downarrow$ & $\downarrow$ & $\downarrow$ \\
\hline $\begin{array}{l}\text { Glutamate } \\
\text { HMDB0000148 }\end{array}$ & $\begin{array}{l}2.059(\mathrm{~m}), 2.140(\mathrm{~m}), 2.355(\mathrm{~m}) \\
3.761(\mathrm{dd})\end{array}$ & $\downarrow$ & $\downarrow$ & - & $\downarrow$ & - & $\downarrow$ & - \\
\hline $\begin{array}{l}\text { Glutamine } \\
\text { HMDB0000641 }\end{array}$ & $2.145(\mathrm{~m}), 2.460(\mathrm{~m}), 3.783(\mathrm{t})$ & - & $\downarrow$ & $\downarrow$ & $\downarrow$ & $\downarrow$ & $\downarrow$ & $\downarrow$ \\
\hline $\begin{array}{l}\text { Glutathione } \\
\text { HMDB0000125 }\end{array}$ & $\begin{array}{l}2.171(\mathrm{~m}), 2.560(\mathrm{~m}) \\
2.935(\mathrm{dd}), 2.980(\mathrm{dd}), \\
3.782(\mathrm{~m}), 4.572(\mathrm{dd})\end{array}$ & - & - & - & $\downarrow$ & - & $\downarrow$ & - \\
\hline $\begin{array}{l}\text { Succinate } \\
\text { HMDB0000254 }\end{array}$ & $2.406(\mathrm{~s})$ & - & - & - & $\downarrow$ & $\downarrow$ & $\downarrow$ & - \\
\hline $\begin{array}{l}\text { Aspartate } \\
\text { HMDB0000191 }\end{array}$ & $2.684(\mathrm{dd}), 2.816(\mathrm{dd}), 3.902(\mathrm{dd})$ & $\downarrow$ & $\downarrow$ & $\downarrow$ & $\uparrow$ & $\uparrow$ & - & $\uparrow$ \\
\hline $\begin{array}{l}\text { Creatine } \\
\text { HMDB0000064 }\end{array}$ & $3.041(\mathrm{~s}), 3.931(\mathrm{~s})$ & - & - & - & - & - & $\downarrow$ & - \\
\hline $\begin{array}{l}\text { Creatine phosphate } \\
\text { HMDB0001511 }\end{array}$ & $3.045(\mathrm{~s}), 3.95(\mathrm{~s})$ & $\downarrow$ & - & - & - & $\uparrow$ & $\uparrow$ & $\downarrow$ \\
\hline $\begin{array}{l}\text { Choline } \\
\text { HMDB0000097 }\end{array}$ & $3.205(\mathrm{~s})$ & - & - & - & $\uparrow$ & - & $\downarrow$ & $\uparrow$ \\
\hline $\begin{array}{l}\text { Phosphoryl-choline } \\
\text { HMDB0001565 }\end{array}$ & $3.224(\mathrm{~s}), 3.597(\mathrm{~s}), 4.171(\mathrm{~m})$ & $\downarrow$ & $\downarrow$ & - & - & - & - & $\downarrow$ \\
\hline $\begin{array}{l}\text { Glycerophospho-choline } \\
\text { HMDB00086 }\end{array}$ & $3.234(\mathrm{~s}), 4.33(\mathrm{~m})$ & $\uparrow$ & - & - & $\downarrow$ & $\downarrow$ & $\downarrow$ & $\downarrow$ \\
\hline $\begin{array}{l}\text { Taurine } \\
\text { HMDB0000251 }\end{array}$ & $3.269(\mathrm{t}), 3.425(\mathrm{t})$ & $\downarrow$ & - & - & - & $\uparrow$ & $\downarrow$ & $\uparrow$ \\
\hline $\begin{array}{l}\text { Myo-inositol } \\
\text { HMDB0000211 }\end{array}$ & $\begin{array}{l}3.284(\mathrm{t}), 3.540(\mathrm{dd}), 3.626(\mathrm{dd}) \\
\quad 4.067(\mathrm{t})\end{array}$ & $\uparrow$ & $\downarrow$ & - & $\uparrow$ & - & - & - \\
\hline $\begin{array}{l}\text { Inosine } \\
\text { HMDB0000195 }\end{array}$ & $\begin{array}{l}3.845(\mathrm{dd}), 3.915(\mathrm{dd}), 4.282(\mathrm{~m}) \\
\quad 4.442(\mathrm{dd}), 6.105(\mathrm{~d}), 8.241(\mathrm{~s}) \\
8.348(\mathrm{~s})\end{array}$ & $\uparrow$ & - & $\uparrow$ & $\uparrow$ & $\uparrow$ & $\uparrow$ & $\uparrow$ \\
\hline $\begin{array}{l}\text { Glucose } \\
\text { HMDB0000122 }\end{array}$ & $4.652(d), 5.239(d)$ & $\uparrow$ & $\uparrow$ & - & - & - & - & - \\
\hline $\begin{array}{l}\text { Uridine } \\
\text { HMDB0000296 }\end{array}$ & $5.907(d), 5.922(d), 7.877(d)$ & $\uparrow$ & - & $\uparrow$ & $\uparrow$ & $\uparrow$ & $\uparrow$ & $\uparrow$ \\
\hline $\begin{array}{l}\text { GTP } \\
\text { HMDB0001273 }\end{array}$ & $5.945(\mathrm{~d}), 8.14(\mathrm{~s})$ & $\downarrow$ & $\downarrow$ & - & $\downarrow$ & $\downarrow$ & $\downarrow$ & $\downarrow$ \\
\hline
\end{tabular}


Table 1 (continued)

\begin{tabular}{|c|c|c|c|c|c|c|c|c|}
\hline Metabolite & $\begin{array}{l}{ }^{1} \mathrm{H} \text { NMR parameters: chemi- } \\
\text { cal shift in ppm (multiplicity, } \mathrm{d} \\
\text { doublet, m multiplet, s singlet, } \mathrm{t} \\
\text { triplet) }\end{array}$ & $\begin{array}{l}\text { G13D/+ } \\
\text { vs }+/+\end{array}$ & $\begin{array}{l}\text { G12S/+ } \\
\text { vs +/+ }\end{array}$ & $\begin{array}{l}G 12 A /+ \\
\text { vs }+/+\end{array}$ & $\begin{array}{l}\text { G12C/+ } \\
\text { vs +/+ }\end{array}$ & $\begin{array}{l}G 12 D /+ \\
\text { vs }+/+\end{array}$ & $\begin{array}{l}\text { G12V/+ } \\
\text { vs +/+ }\end{array}$ & $\begin{array}{l}G 12 R /+ \\
\text { vs }+/+\end{array}$ \\
\hline $\begin{array}{l}\text { UMP } \\
\text { HMDB0000288 }\end{array}$ & $5.97(\mathrm{~d}), 8.11(\mathrm{~d})$ & $\downarrow$ & - & - & $\downarrow$ & $\downarrow$ & $\downarrow$ & - \\
\hline $\begin{array}{l}\text { NAD } \\
\text { HMDB0000902 }\end{array}$ & $\begin{array}{c}6.044(\mathrm{~d}), 6.09(\mathrm{~d}), 8.18(\mathrm{~s}), 8.20 \\
8.43(\mathrm{~s}), 8.84(\mathrm{~m}), 9.15,9.34\end{array}$ & - & - & - & - & $\downarrow$ & $\downarrow$ & - \\
\hline $\begin{array}{l}\text { Fumarate } \\
\text { HMDB00134 }\end{array}$ & $6.521(\mathrm{~s})$ & $\downarrow$ & - & - & $\uparrow$ & - & - & - \\
\hline $\begin{array}{l}\text { Tyrosine } \\
\text { HMDB00158 }\end{array}$ & $6.91(\mathrm{~m}), 7.20(\mathrm{~m})$ & $\downarrow$ & - & $\downarrow$ & $\downarrow$ & $\downarrow$ & $\downarrow$ & - \\
\hline $\begin{array}{l}\text { Phenylalanine } \\
\text { HMDB00159 }\end{array}$ & $7.34(\mathrm{~d}), 7.381(\mathrm{~m}), 7.43(\mathrm{~m})$ & $\downarrow$ & - & $\downarrow$ & $\downarrow$ & $\downarrow$ & $\downarrow$ & - \\
\hline $\begin{array}{l}\text { AMP } \\
\text { HMDB00045 }\end{array}$ & $8.273(\mathrm{~s}), 8.614(\mathrm{~s})$ & $\downarrow$ & - & $\downarrow$ & $\downarrow$ & $\downarrow$ & $\downarrow$ & $\downarrow$ \\
\hline $\begin{array}{l}\text { ATP } \\
\text { HMDB00538 }\end{array}$ & $8.275(\mathrm{~s}), 8.538(\mathrm{~s})$ & $\downarrow$ & - & $\downarrow$ & $\downarrow$ & $\downarrow$ & $\downarrow$ & - \\
\hline
\end{tabular}

Table 2 Intracellular metabolites discriminating between $K R A S^{G 13 D /+}$ and $K R A S^{+/+}$

\begin{tabular}{llllr}
\hline Metabolite $^{\mathrm{a}}$ & $\mathrm{ppm}$ & $\mathrm{p}$-values & q-values & Log $_{2} \mathrm{FC}$ \\
\hline Leucine & 0.965 & $9.83 \mathrm{E}-03$ & $7.24 \mathrm{E}-02$ & -0.352 \\
Isoleucine & 1.009 & $3.20 \mathrm{E}-03$ & $3.62 \mathrm{E}-02$ & -0.405 \\
Valine & 1.041 & $3.68 \mathrm{E}-03$ & $3.93 \mathrm{E}-02$ & -0.403 \\
Glutamate & 2.340 & $8.67 \mathrm{E}-03$ & $6.67 \mathrm{E}-02$ & -0.382 \\
Glutamine & 2.440 & 0.010368 & 0.075063 & -0.167 \\
Aspartate & 2.704 & $1.25 \mathrm{E}-03$ & $2.12 \mathrm{E}-02$ & -0.412 \\
Creatine phosphate & 3.045 & $1.44 \mathrm{E}-02$ & $9.28 \mathrm{E}-02$ & -1.060 \\
Phosphocholine & 3.224 & $3.76 \mathrm{E}-04$ & $1.09 \mathrm{E}-02$ & -0.733 \\
Glycerophosphocholine & 3.234 & $1.07 \mathrm{E}-03$ & $1.94 \mathrm{E}-02$ & 0.590 \\
Taurine & 3.428 & $1.16 \mathrm{E}-03$ & $2.04 \mathrm{E}-02$ & -0.776 \\
Myo-inositol & 4.067 & $5.05 \mathrm{E}-04$ & $1.28 \mathrm{E}-02$ & 0.681 \\
AMP & 4.518 & $8.57 \mathrm{E}-04$ & $1.74 \mathrm{E}-02$ & -0.705 \\
Glucose & 5.235 & $1.26 \mathrm{E}-02$ & $8.52 \mathrm{E}-02$ & 0.646 \\
UDP- $N$-acetylglucosamine & 5.512 & $2.56 \mathrm{E}-05$ & $3.28 \mathrm{E}-03$ & 0.659 \\
UDP- $N$-acetylgalactosa- & 5.546 & $9.92 \mathrm{E}-06$ & $2.93 \mathrm{E}-03$ & 0.375 \\
$\quad$ mine & & & & \\
Uridine & 5.900 & $6.47 \mathrm{E}-03$ & $5.54 \mathrm{E}-02$ & 0.284 \\
Fumarate & 6.521 & $9.21 \mathrm{E}-04$ & $1.80 \mathrm{E}-02$ & -0.281 \\
Tyrosine & 6.899 & $5.57 \mathrm{E}-03$ & $5.06 \mathrm{E}-02$ & -0.163 \\
Phenylalanine & 7.329 & $5.17 \mathrm{E}-03$ & $4.84 \mathrm{E}-02$ & -0.177 \\
UMP & 8.105 & $1.61 \mathrm{E}-03$ & $2.47 \mathrm{E}-02$ & -0.483 \\
GTP & 8.140 & $5.87 \mathrm{E}-04$ & $1.40 \mathrm{E}-02$ & -0.238 \\
Inosine & 8.349 & $2.25 \mathrm{E}-05$ & $3.24 \mathrm{E}-03$ & 1.739 \\
ATP & 8.537 & $1.87 \mathrm{E}-03$ & $2.68 \mathrm{E}-02$ & -0.363 \\
AMP & 8.605 & $1.53 \mathrm{E}-03$ & $2.39 \mathrm{E}-02$ & -1.435 \\
\hline & & & & \\
& & & &
\end{tabular}

${ }^{\mathrm{a}}$ For HMDB ID numbers, see Table 1 above

$F C$ fold change

\subsection{Extracellular metabolic profiling of isogenic KRAS wild type and CRC cells with mutation in codon 12 and 13}

To better understand metabolite excretion or utilization by cells, we also compared the extracellular metabolite profiles of the SW48 colorectal cell lines with KRAS mutation in either codon 12 or 13 with their corresponding KRAS wild type cells. Supplementary Fig. 13 shows representative (1D) ${ }^{1} \mathrm{H}$ NMR spectra of culture media (Opti-MEM Medium) from three of these SW48 isogenic cell line $\left(K R A S^{G 13 D /+}\right.$, $K R A S^{G 12 D /+}$ and $K R A S^{+/+}$).

PCA Analysis, showed that all mutant colorectal cancer cell lines were clearly separated from the wild-type KRAS controls (Supplementary Fig. 14). Whilst several KRAS mutants overlapped with each other, samples of KRAS G12D and KRAS G12S deviated from the rest of KRAS mutants, and KRAS G12D clustered closer to the KRAS WT.

Maximum margin criterion (MMC, Supplementary Fig. 15) analysis was also performed (Veselkov et al. 2014) and validated (Supplementary Fig. 16) and ANOVA with an FDR of 0.1 identified metabolites responsible for the group separations (Supplementary Figs. 17-23).

Table 3 lists the statistically significant extracellular metabolites discriminating between SW48 cell lines harbouring KRAS mutations in codon 12 and 13 and their matched wild type cells.

Some metabolites showed similar patterns of changes in the majority of the KRAS mutant cells. For instance, all KRAS mutants, with the exception of G13D, G12D and G12S, showed an elevated uptake of glucose and release of lactate compared to their matched KRAS wild type cells. In addition, an increased uptake of methionine is 


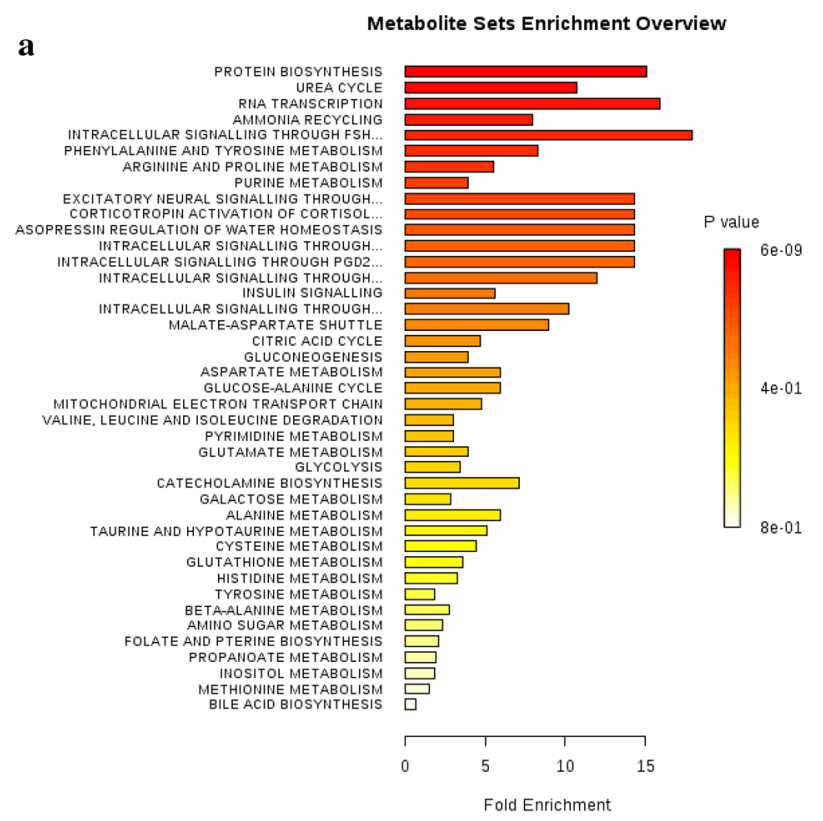

b

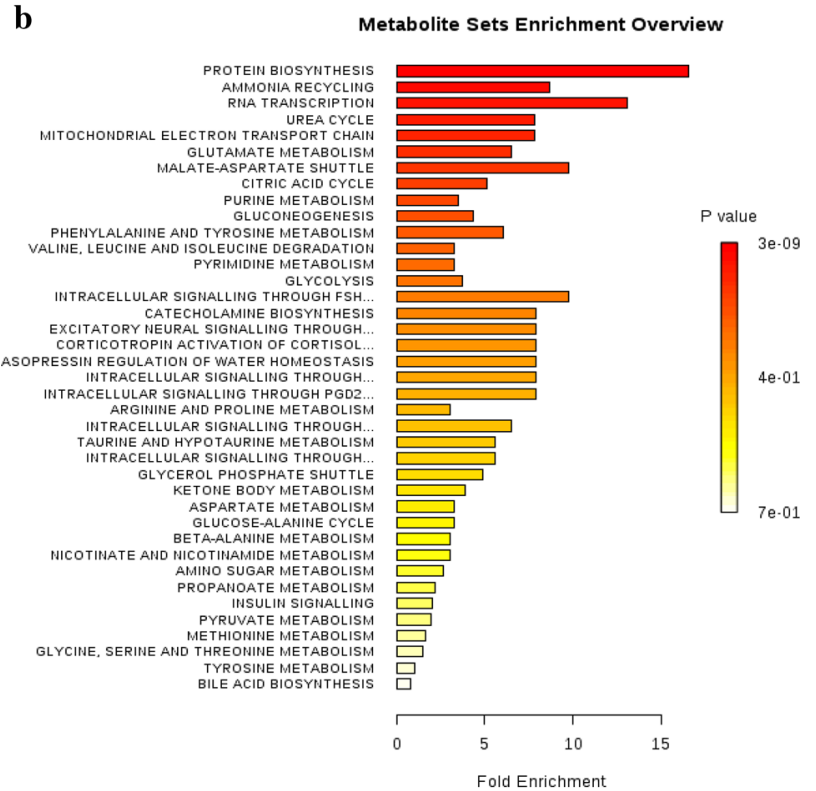

Fig. 3 Metabolic pathway analyses for metabolites discriminating between a $\mathrm{KRAS}^{\mathrm{G} 13 \mathrm{D} /+}$ and $\mathrm{KRAS}^{+/+}$b $\mathrm{KRAS}^{\mathrm{G} 12 \mathrm{D} /+}$ and $\mathrm{KRAS}^{+/+}$. The horizontal bars summarize the main metabolite sets identified in this analysis; the bars are coloured based on their p-values and the length is based on the fold enrichment

observed in all KRAS mutant cell lines apart from G12D. Moreover, L-alanyl-L-glutamine was decreased across all KRAS mutant cell lines except G12C and G12S. However, nutrient utilization generally was varied among colorectal cancer cell lines with different KRAS mutations (see Supplementary Information p. 34 and Supplementary Tables 10-16).

\subsection{Intracellular metabolic profiling of isogenic KRAS wild type and CRC cells with KRAS mutations in codon 61 and 146}

Representative annotated NMR spectra for each mutant and WT samples are shown in Supplementary Fig. 24. PCA revealed clear separation of each mutant from KRAS WT (Supplementary Fig. 25). Maximum margin criterion analysis was conducted (Supplementary Fig. 26) (Veselkov et al. 2014) and leave-one-out cross-validation with the quadratic as a classifier (Supplementary Fig. 27) gave correct classification rates of $100 \%$ for all models. Supplementary Figs. 28-30 show the representative ANOVA built between $\left(K R A S^{A 146 T /+}\right.$ vs $\left.K R A S^{+/+}\right),\left(K R A S^{Q 61 H /+}\right.$ vs $\left.K R A S^{+/+}\right)$and $\left(K R A S^{A 146 T /+}\right.$ vs $\left.K R A S^{Q 61 H /+}\right)$ respectively. Supplementary Table 17 lists the most significant metabolites responsible for discriminating between all three genotypes. KRAS mutations at codon 61 and 146 mostly downregulated metabolites relative to the WT, as observed in cells harbouring KRAS mutations in codon 12 and 13.

Both A146T and Q61H KRAS mutations induced alteration of the same metabolic pathways with protein biosynthesis being the most enriched pathways in both mutations (Supplementary Fig. 31 and Supplementary Tables 18 and 19). Interestingly, the least metabolic changes were observed between $K R A S^{A 146 T /+}$ and $K R A S^{Q 61 H /+}$.

\section{Discussion}

Mutations in the Kirsten Ras (KRAS) oncogene occur in $30-40 \%$ of colorectal cancers (CRCs) and have been associated with poor prognosis and resistance to anti-epidermal growth factor receptor (EGFR)-targeted cancer therapy (Andreyev et al. 2001; Arrington et al. 2012; Misale et al. 2014, 2012; Phipps et al. 2013; Tougeron et al. 2013) such as the monoclonal antibody panitumumab. Recent evidence indicates that not all mutations in KRAS have the same biological impact and patients with different KRAS mutations at codons 12 and 13 display different responses to treatments (Garassino et al. 2011; Miller and Miller 2011; Stolze et al. 2015; Tural et al. 2013).

The oncogene KRAS plays a critical role in metabolic reprogramming and metabolic interventions are now attracting attention as potential therapeutic modalities (Kawada et al. 2017; Kimmelman 2015). Metabonomics can thus be regarded as a promising tool to gain more insight into metabolic deregulation associated with different KRAS mutations, which in turn can be used to discover new therapeutic approaches and better direct existing treatments of CRC.

We note that the impact of KRAS on cell growth is only evident when cells are challenged by changing their environment, such that the impact of a dominant oncogene becomes 
Table 3 Summary of the most significant extracellular metabolites differentiating between media of SW48 cells with KRAS mutations in codons 12 and 13 and media of their wild type counterpart

\begin{tabular}{|c|c|c|c|c|c|c|c|c|}
\hline Metabolite (HMDB no) & $\begin{array}{l}{ }^{1} \mathrm{H} \text { NMR chemical shift in ppm and } \\
\text { multi-plicity }\end{array}$ & $\begin{array}{l}G 13 D /+ \\
\text { vs }+/+\end{array}$ & $\begin{array}{l}\text { G12S/+ } \\
\text { vs }+/+\end{array}$ & $\begin{array}{l}\text { G12A/+ } \\
\text { vs }+/+\end{array}$ & $\begin{array}{l}\text { G12C/+ } \\
\text { vs }+/+\end{array}$ & $\begin{array}{l}G 12 D /+ \\
\text { vs }+/+\end{array}$ & $\begin{array}{l}G 12 \mathrm{~V} /+ \\
\text { vs }+/+\end{array}$ & $\begin{array}{l}G 12 R /+ \\
\mathrm{vs}+/+\end{array}$ \\
\hline $\begin{array}{l}\text { 3-methyl-2-oxo-valeric acid } \\
\text { (00491) }\end{array}$ & $0.897(\mathrm{t}), 1.102(\mathrm{~d})$ & $\downarrow$ & - & - & $\uparrow$ & - & $\downarrow$ & $\uparrow$ \\
\hline keto-leucine (00695) & $0.94(\mathrm{~d}), 2.617(\mathrm{~d})$ & $\downarrow$ & - & $\downarrow$ & - & - & $\downarrow$ & - \\
\hline Isoleucine (00172) & $0.943(\mathrm{t}), 1.01(\mathrm{~d}), 3.675(\mathrm{~d})$ & - & - & - & $\downarrow$ & - & - & $\downarrow$ \\
\hline Leucine (00687) & $\begin{array}{l}0.961(\mathrm{~d}), 0.972(\mathrm{~d}), 1.691(\mathrm{~m}) \\
1.720(\mathrm{~m}), 1.748(\mathrm{~m}), 3.737(\mathrm{dd})\end{array}$ & - & - & - & $\downarrow$ & - & - & $\downarrow$ \\
\hline Valine (00883) & $0.996(\mathrm{~d}), 1.046(\mathrm{~d}), 3.615(\mathrm{~d})$ & - & - & - & $\downarrow$ & - & - & $\downarrow$ \\
\hline 2-Oxo-isovaleric acid (00019) & $1.126(\mathrm{~d})$ & $\downarrow$ & - & - & - & - & $\downarrow$ & $\uparrow$ \\
\hline Lactate (00190) & $1.331(\mathrm{~d}), 4.113(\mathrm{q})$ & $\downarrow$ & $\downarrow$ & $\uparrow$ & $\uparrow$ & - & $\uparrow$ & $\uparrow$ \\
\hline Threonine (00167) & $1.335(\mathrm{~d}), 3.591(\mathrm{~d})$ & $\downarrow$ & - & - & - & - & - & - \\
\hline Alanine (00161) & $1.48(\mathrm{~d}), 3.787(\mathrm{q})$ & - & $\downarrow$ & - & - & $\uparrow$ & $\uparrow$ & - \\
\hline L-Alanyl-L-glutamine (0028685) & $1.546(\mathrm{~d}), 1.98(\mathrm{~m}), 2.35(\mathrm{t}), 4.182$ & $\downarrow$ & $\uparrow$ & $\downarrow$ & - & $\downarrow$ & $\downarrow$ & $\downarrow$ \\
\hline Acetate $(00042)$ & $1.919(\mathrm{~s})$ & $\uparrow$ & $\uparrow$ & $\uparrow$ & $\downarrow$ & - & - & $\downarrow$ \\
\hline Glutamate (00148) & $\begin{array}{l}2.059(\mathrm{~m}), 2.140(\mathrm{~m}), 2.355(\mathrm{~m}) \\
3.761(\mathrm{dd})\end{array}$ & $\uparrow$ & - & - & - & - & $\uparrow$ & $\uparrow$ \\
\hline Glutamine (00641) & $2.145(\mathrm{~m}), 2.46(\mathrm{~m}), 3.783(\mathrm{t})$ & - & $\downarrow$ & - & - & $\uparrow$ & - & - \\
\hline Methionine (0000696) & $2.1(\mathrm{~s}), 2.65(\mathrm{t})$ & $\downarrow$ & $\downarrow$ & $\downarrow$ & $\downarrow$ & - & $\downarrow$ & $\downarrow$ \\
\hline Pyruvate (0000243) & $2.379(\mathrm{~s})$ & - & - & - & - & $\uparrow$ & $\uparrow$ & - \\
\hline Aspartate (00191) & $2.684(\mathrm{dd}), 2.816(\mathrm{dd}), 3.902(\mathrm{dd})$ & - & - & - & - & - & - & $\downarrow$ \\
\hline Glucose (00122) & $4.65(\mathrm{~d}), 5.2(\mathrm{~d})$ & - & - & $\downarrow$ & $\downarrow$ & - & $\downarrow$ & $\downarrow$ \\
\hline Histidine (00177) & $7.115(\mathrm{~d}), 7.922(\mathrm{~d})$ & - & - & - & - & - & - & $\downarrow$ \\
\hline Tyrosine (0000158) & $6.91(\mathrm{~m}), 7.20(\mathrm{~m})$ & - & - & - & - & - & - & $\downarrow$ \\
\hline Phenyl-alanine (0000159) & $7.34(\mathrm{~d}), 7.381(\mathrm{~m}), 7.43(\mathrm{~m})$ & $\downarrow$ & - & - & $\downarrow$ & - & $\downarrow$ & $\downarrow$ \\
\hline Tryptophan (0000929) & $7.55(\mathrm{~d}), 7.75(\mathrm{~d}), 7.29(\mathrm{~s})$ & $\downarrow$ & - & $\downarrow$ & $\downarrow$ & - & - & $\downarrow$ \\
\hline Formate (0000142) & $8.461(\mathrm{~s})$ & - & - & - & - & - & $\downarrow$ & $\downarrow$ \\
\hline
\end{tabular}

more apparent. The effects of mutant KRAS in adherent cells, such as SW48, growing on tissue culture plastic is not evident (i.e. the cells are not dependent on mutant KRAS for proliferation or survival under these conditions). However, the impact of mutant KRAS is apparent in adherent cells when they are cultured either on soft agar, or in low adherence plates in the absence of foetal calf serum, and hence we selected these conditions. In addition, we selected a short cell incubation time of $6 \mathrm{~h}$, as we wanted to understand the initial impact that mutant KRAS has on metabolism in cells under conditions where mutant KRAS has the most substantial impact.

Following a thorough multivariate and FDR-controlled univariate analysis of the ${ }^{1} \mathrm{H}$ NMR spectra, we observed a clear distinction in both the extracellular (media) and intracellular metabolic profiles of the KRAS mutant cells versus the KRAS wildtype cells.

The analysis of the extracellular media revealed increased glucose consumption and lactate release in KRAS G12A, KRAS G12C, KRAS G12V and KRAS G12R compared to KRAS wild type cell lines. These metabolic changes could indicate enhanced glycolytic flux in these KRAS mutants.
This is consistent with the Warburg effect(Vander Heiden et al. 2009; Warburg 1956) and in accordance with previous studies reporting enhanced glucose uptake in cells with mutant KRAS through increased expression of the glucose transporter GLUT1, which subsequently results in increased glycolysis and lactate production (Bryant et al. 2014; Kawada et al. 2017; Yun et al. 2009). Interestingly, lower levels of lactate were observed in the extracellular media of KRAS G13D and KRAS G12S and intracellular extracts of KRAS G12D compared to their wild type counterpart. This implies that glycolytic flux and lactate production are affected by specific mutations in KRAS. It is already known that a glycolytic switch occurs in KRAS ${ }^{G 12 D / G 12 D}$ cells (Kerr et al. 2016).

Decreased levels i.e. elevated consumption of extracellular methionine were observed in all KRAS mutant cell lines, with the exception of G12D, relative to their KRAS wild type counterpart. Methionine is a sulfur-containing, essential amino acid that plays a critical role in many biological functions within carcinogenic processes. Methionine is involved in cellular processes and is the immediate precursor of S-adenosyl methionine (SAMe), which is a 
substrate for polyamine synthesis and a key metabolite in one-carbon metabolism, serving as a major methyl donor in a multitude of cellular methylation reactions, including the methylation of cytosine bases on DNA (Cavuoto and Fenech 2012). Aberrations in DNA methylation have been shown to be associated with colorectal carcinogenesis (Kim 2004). Many cancer-cell types exhibit an increased requirement for methionine (Vazquez et al. 2016). Thus, methionine restriction can potentially be exploited to treat cancers that exhibit methionine dependency, as diet is known to influence methionine metabolism in addition to methionine pathway mutations (Sanderson et al. 2019a; b).

Decreased levels of the media component L-alanylL-glutamine (stable and non-toxic glutamine source) were found for colorectal cancer cells harbouring G13D, G12A, G12D, G12V and G12R mutations compared to their background-matched KRAS wild type cancer cells. No trace of L-alanyl-L-glutamine was observed in the intracellular matrix indicating either that L-alanyl-L-glutamine is hydrolysed by extracellular peptidase activity, or if it is imported, it remains at low levels undetectable by NMR spectroscopy.

Lowered levels of media L-alanyl-L-glutamine with no changes in extracellular glutamine in KRAS G13D, G12A, G12V and G12R relative to WT KRAS could indicate an elevated glutamine uptake. KRAS G12D also showed significant decrease of L-alanyl-L-glutamine (fold change of ca. 0.16 ) but with a minor increase of extracellular glutamine (fold change of ca. 1.13) compared to WT KRAS, also indicating enhanced glutamine uptake. KRAS G12C, however, displayed no changes in either L-alanyl-L-glutamine or extracellular glutamine compared to WT KRAS, which is interesting as this specific KRAS mutation is now targeted with drugs in the clinic.(Canon et al. 2019; Hallin et al. 2019; Seton-Rogers. 2019) Finally, KRAS G12S showed less glutamine uptake as suggested by higher levels of L-alanylL-glutamine and lower levels of extracellular glutamine indicating less hydrolysis of the dipeptide. Notably, all KRAS mutants, with the exception of KRAS G13D, showed lower intracellular levels of glutamine indicating increased glutamine consumption.

Glutamine is one of the most important nutrients that is metabolised by many human cancer cell lines. Despite being a non-essential amino acid (NEAA) that can be synthesized de novo, many cancer cells in vitro largely depend on exogenous glutamine for their growth, proliferation, and survival (Choi and Park 2018). Once imported into the cells, glutamine provides a carbon source to fuel the tricarboxylic acid (TCA) cycle and a nitrogen source for the biosynthesis of nucleotides, NEAA and hexosamines (Kawada et al. 2017). Cancer cells, particularly those harbouring oncogenic KRAS, have been shown to be heavily dependent on glutamine for survival and proliferation (Choi and Park 2018). Overall, our observations suggest that $K R A S$ mutations generally induce glutamine dependency with different mutations showing different extents of dependency on extracellular glutamine.

Analysis of the intracellular metabolic profile of the isogenic cell lines also showed significant variation in a number of metabolic pathways between WT KRAS-expressing cells and all the other mutants. The main alterations associated with mutant KRAS involved changes in amino acid and nucleotide metabolism as well as in the hexosamine biosynthesis pathway.

Intracellular glutamate levels were decreased in most KRAS mutant colorectal cancer cells (KRAS G13D, KRAS G12S, KRAS G12C and KRAS G12V). Intracellular glutamate is primarily a product of glutamine, which is produced by the action of glutaminase (Kawada et al. 2017). Low intracellular levels of glutamine and glutamate in KRAS mutant cells compared to their isogenic wildtype cell lines could indicate sustained biosynthetic reactions and a prominent role of glutaminolysis.

Interestingly, we also observed enhanced intracellular metabolism of other amino acids such as tyrosine, phenylalanine, and the branched chain amino acids (BCAAs) leucine, isoleucine, and valine in all KRAS mutants, with the exception of G12S and G12R, compared to their wild type counterpart. BCAAs are essential for cancer growth and are used by cancer cells in various biosynthetic pathways and as a source of energy (Ananieva and Wilkinson 2018). Previous studies have highlighted that leucine, isoleucine, valine, tyrosine and phenylalanine contribute to the TCA cycle via conversion into succinate and fumarate (Owen et al. 2002; Tripathi et al. 2012). Mayers et al. reported that elevated patient plasma BCAA levels were associated with an increased risk of future pancreatic cancer (Mayers et al. 2014). They also reported that changes in BCAA levels in $K R A S$-driven tumours in mice were tissue specific (Mayers et al. 2016).

All KRAS mutants except G12C showed decreased intracellular levels of UDP-GlcNAc while KRAS G13D exhibited an increased amount of UDP-GlcNAc relative to the wild type. UDP-GalNAc was also decreased in all KRAS mutants except G12C, A146T and Q61H compared to the WT counterpart while G13D showed increased levels. Cancer cells generally exhibit upregulation of the hexosamine biosynthetic pathway (HBP), which is in turn linked to aberrant $O$-GlcNAcylation and an enhanced malignant phenotype (Ferrer et al. 2014; Wong et al. 2017; Yi et al. 2012). Hyper $O$-GlcNAcylation has been reported in PDAC and this modification has been suggested to aid evading of apoptosis (Bryant et al. 2014). Kucharzewska et al. (2015) reported decreased UDP-Gal and UDP-GlcNAc/UDP-GalNAc in hypoxic cancer cells, indicating increased demand of for the synthesis of glycoproteins and glycolipids. In the present study, alterations in the concentrations of UDP-GlcNAc and UDP-GalNAc in almost all of KRAS mutants relative 
to their wild type counterparts could indicate changes in protein glycosylation and HBP synthesis pathway.

Compared to KRAS WT, all KRAS mutants except G12S demonstrated increased levels of inosine and uridine together with decreased levels of AMP, whilst cell lines with the KRAS A146T mutations showed no such changes and KRAS Q61H just exhibited decreased levels of AMP. The levels of ATP, GTP and UMP were also reduced in most KRAS mutant colorectal cancer cells compared to their corresponding wild type. However, in direct contrast, KRAS A146T displayed increased levels of GTP and ATP. Nucleotide pool imbalance has been proposed to be associated with enhanced mutagenesis and genomic instability, which promotes cancer (Kohnken et al. 2015; Papadopoulou et al. 2015). Deregulation of nucleotide metabolism is associated with a wide range of pathological conditions including cancer (Buj and Aird 2018; Kohnken et al. 2015). In the present study, the significant increase of nucleosides (inosine, uridine) together with decrease of nucleotides (AMP, UMP) in the KRAS mutants could reflect rapid nucleotide turnover and salvage pathway activity of nucleic acid metabolism.

\section{Conclusion}

We carried out a comprehensive, unbiased metabonomic analysis of human colorectal cell lines (SW48) harbouring a wide range of specific KRAS mutations on common genetic backgrounds to broaden and deepen our understanding of the relationships between specific genotypes and metabolic phenotypes, or metabotypes, in human colorectal cancer cells. Our data further support the notion that KRAS mutations trigger metabolic adaptations to help growth and counter stress. Furthermore, this study highlights that colorectal cancer cells carrying different $K R A S$ mutations exhibit specific metabolic phenotypes, including differences in glycolysis, glutamine utilization, and amino acid, choline and nucleotide hexosamine metabolism. These metabolic differences between different $K R A S$ mutants might play a role in their different responses to anticancer treatments and hence could be investigated to discover novel metabolic vulnerabilities which might be of utility in the development of more effective targeted therapies against oncogenic KRAS. Future studies could also investigate the relative roles of genetic mutation and nutrient availability in directing the metabolic phenotypes of specific cancer cells.

Acknowledgements We thank Clare Sheridan and Glynn Martin for assistance with cell culture. We thank Professors Jeremy Nicholson and Elaine Holmes for access to NMR facilities at Imperial College London and we thank Dr. Beatriz Jiminez and her team there for technical assistance.
Author contributions Conceptualizing, refining and funding research ideas: JRE and NMcC. Literature search: DV. Creating research design: Dorna V, NMcC and JRE. Statistical analyses and computations: KV, DV and DV. Collection and preparation of data: DV, DV, JRE. Drafting, editing and approving manuscript: DV, DV, NMcC, KV, HK, JRE.

Funding We thank the University of Greenwich and Horizon Discovery for funding.

Data availability Original NMR data are deposited in MetaboLights, EBI, Cambridge UK following publication: https://www.ebi.ac.uk/ metabolights/. These data have the code MTBLS1620 (Kenneth Haug, Keeva Cochrane, Venkata Chandrasekhar Nainala, Mark Williams, Jiakang Chang, Kalai Vanii Jayaseelan, Claire O'Donovan. MetaboLights: a resource evolving in response to the needs of its scientific community. Nucleic Acids Research, gkz1019, https://doi.org/10.1093/nar/gkz10 19, PMID:31691833).

\section{Compliance with ethical standards}

Conflicts of interest Nicola McCarthy is an employee of Horizon Discovery. All other authors declare that they have no conflict of interest.

Ethical approval No animals or human subjects were involved in this study, which complied with all University ethical and safety standards.

Open Access This article is licensed under a Creative Commons Attribution 4.0 International License, which permits use, sharing, adaptation, distribution and reproduction in any medium or format, as long as you give appropriate credit to the original author(s) and the source, provide a link to the Creative Commons licence, and indicate if changes were made. The images or other third party material in this article are included in the article's Creative Commons licence, unless indicated otherwise in a credit line to the material. If material is not included in the article's Creative Commons licence and your intended use is not permitted by statutory regulation or exceeds the permitted use, you will need to obtain permission directly from the copyright holder. To view a copy of this licence, visit http://creativecommons.org/licenses/by/4.0/.

\section{References}

Ananieva, E. A., \& Wilkinson, A. C. (2018). Branched-chain amino acid metabolism in cancer. Current Opinion in Clinical Nutrition and Metabolic Care, 21(1), 64-70.

Andreyev, H. J., Norman, A. R., Cunningham, D., Oates, J., Dix, B. R., Iacopetta, B. J., et al. (2001). Kirsten ras mutations in patients with colorectal cancer: the 'RASCAL II' study. British Journal of Cancer, 85(5), 692-696.

Arena, S., Pisacane, A., Mazzone, M., Comoglio, P. M., \& Bardelli, A. (2007). Genetic targeting of the kinase activity of the Met receptor in cancer cells. Proceedings of the National Academy of Sciences of the United States of America, 104(27), 11412-11417.

Arrington, A. K., Heinrich, E. L., Lee, W., Duldulao, M., Patel, S., Sanchez, J., et al. (2012). Prognostic and predictive roles of KRAS mutation in colorectal cancer. International Journal of Molecular Sciences, 13(10), 12153-12168.

Benjamini, Y. (2010). Discovering the false discovery rate. Journal of the Royal Statistical Society Series B, 72, 405-416.

Brunelli, L., Caiola, E., Marabese, M., Broggini, M., \& Pastorelli, R. (2014). Capturing the metabolomic diversity of KRAS mutants in non-small-cell lung cancer cells. Oncotarget, 5(13), 4722-4731. 
Bryant, K. L., Mancias, J. D., Kimmelman, A. C., \& Der, C. J. (2014). KRAS: Feeding pancreatic cancer proliferation. Trends in Biochemical Sciences, 39(2), 91-100.

Buj, R., \& Aird, K. M. (2018). Deoxyribonucleotide triphosphate metabolism in cancer and metabolic disease. Frontiers in Endocrinology, 9, 177.

Canon, J., Rex, K., Saiki, A. Y., Mohr, C., Cooke, K., Bagal, D., et al. (2019). The clinical KRAS(G12C) inhibitor AMG 510 drives antitumour immunity. Nature, 575(7781), 217.

Cavuoto, P., \& Fenech, M. F. (2012). A review of methionine dependency and the role of methionine restriction in cancer growth control and life-span extension. Cancer Treatment Reviews, 38(6), 726-736.

Choi, Y.-K., \& Park, K.-G. (2018). Targeting glutamine metabolism for cancer treatment. Biomolecules \& Therapeutics, 26(1), 19-28.

Dieterle, F., Ross, A., Schlotterbeck, G., \& Senn, H. (2006). Probabilistic quotient normalization as robust method to account for dilution of complex biological mixtures. Application in 1H NMR metabonomics. Analytical Chemistry, 78(13), 4281-4290.

Dinu, D., Dobre, M., Panaitescu, E., Bîrlă, R., Iosif, C., Hoara, P., et al. (2014). Prognostic significance of KRAS gene mutations in colorectal cancer: Preliminary study. Journal of Medicine and Life, 7(4), 581-587.

Dona, A. C., Kyriakides, M., Scott, F., Shephard, E. A., Varshavi, D., Veselkov, K., et al. (2016). A guide to the identification of metabolites in NMR-based metabonomics/metabolomics experiments. Computational and Structural Biotechnology Journal, 14, $135-153$.

Everett, J. R. (2015). A new paradigm for known metabolite identification in metabonomics/metabolomics: Metabolite identification efficiency. Computational and Structural Biotechnology Journal, 13, 131-144.

Ferrer, C. M., Lynch, T. P., Sodi, V. L., Falcone, J. N., Schwab, L. P., Peacock, D. L., et al. (2014). O-GlcNAcylation regulates cancer metabolism and survival stress signaling via regulation of the HIF-1 pathway. Molecular Cell, 54(5), 820-831.

Garassino, M. C., Marabese, M., Rusconi, P., Rulli, E., Martelli, O., Farina, G., et al. (2011). Different types of K-Ras mutations could affect drug sensitivity and tumour behaviour in non-small-cell lung cancer. Annals of Oncology, 22, 235-237.

Guarnaccia, M., Iemmolo, R., San Biagio, F., Alessi, E., \& Cavallaro, S. (2018). Genotyping of KRAS mutational status by the in-check lab-on-chip platform. Sensors, 18(1), 131.

Hallin, J., Engstrom, L. D., Hargis, L., Calinisan, A., Aranda, R., Briere, D. M., et al. (2019). The KRASG12C inhibitor, MRTX849, provides insight toward therapeutic susceptibility of KRAS mutant cancers in mouse models and patients. Cancer Discovery, 10, 54-71.

Hammond, D. E., Mageean, C. J., Rusilowicz, E. V., Wickenden, J. A., Clague, M. J., \& Prior, I. A. (2015). Differential reprogramming of isogenic colorectal cancer cells by distinct activating KRAS mutations. Journal of Proteome Research, 14(3), 1535-1546.

Han, B., Kang, H. M., \& Eskin, E. (2009). Rapid and accurate multiple testing correction and power estimation for millions of correlated markers. PLoS Genetics, 5(4), e1000456.

Jia, Y., Jiang, T., Li, X., Zhao, C., Zhang, L., Zhao, S., et al. (2017). Characterization of distinct types of KRAS mutation and its impact on first-line platinum-based chemotherapy in Chinese patients with advanced non-small cell lung cancer. Oncology Letters, 14(6), 6525-6532.

Kawada, K., Toda, K., \& Sakai, Y. (2017). Targeting metabolic reprogramming in KRAS-driven cancers. Int J Clin Oncol, 22(4), $651-659$.

Kerr, E. M., Gaude, E., Turrell, F. K., Frezza, C., \& Martins, C. P. (2016). Mutant Kras copy number defines metabolic reprogramming and therapeutic susceptibilities. Nature, 531(7592), 110
Kim, Y.-I. (2004). Folate and DNA methylation: A mechanistic link between folate deficiency and colorectal cancer? Cancer Epidemiology Biomarkers \& Prevention, 13(4), 511.

Kimmelman, A. C. (2015). Metabolic dependencies in RAS-driven cancers. Clinical Cancer Research, 21(8), 1828-1834.

Kishiki, T., Ohnishi, H., Masaki, T., Ohtsuka, K., Ohkura, Y., Furuse, J., et al. (2014). Impact of genetic profiles on the efficacy of antiEGFR antibodies in metastatic colorectal cancer with KRAS mutation. Oncology Reports, 32(1), 57-64.

Kohnken, R., Kodigepalli, K. M., \& Wu, L. (2015). Regulation of deoxynucleotide metabolism in cancer: Novel mechanisms and therapeutic implications. Molecular Cancer, 14(1), 176.

Kucharzewska, P., Christianson, H. C., \& Belting, M. (2015). Global profiling of metabolic adaptation to hypoxic stress in human glioblastoma cells. PLOS ONE, 10(1), e0116740.

Lievre, A., Bachet, J. B., Le Corre, D., Boige, V., Landi, B., Emile, J. F., et al. (2006). KRAS mutation status is predictive of response to cetuximab therapy in colorectal cancer. Cancer Research, 66(8), 3992-3995.

Margonis, G. A., Kim, Y., Spolverato, G., Ejaz, A., Gupta, R., Cosgrove, D., et al. (2015). Association between specific mutations in KRAS codon 12 and colorectal liver metastasis. JAMA Surgery, $150(8), 722-729$.

Mayers, J. R., Torrence, M. E., Danai, L. V., Papagiannakopoulos, T., Davidson, S. M., Bauer, M. R., et al. (2016). Tissue of origin dictates branched-chain amino acid metabolism in mutant Krasdriven cancers. Science, 353(6304), 1161-1165.

Mayers, J. R., Wu, C., Clish, C. B., Kraft, P., Torrence, M. E., Fiske, B. P., et al. (2014). Elevation of circulating branched-chain amino acids is an early event in human pancreatic adenocarcinoma development. Nature Medicine, 20(10), 1193-1198.

Miller, M. S., \& Miller, L. D. (2011). RAS mutations and oncogenesis: Not all RAS mutations are created equally. Frontier in Genetics, 2, 100.

Misale, S., Di Nicolantonio, F., Sartore-Bianchi, A., Siena, S., \& Bardelli, A. (2014). Resistance to anti-EGFR therapy in colorectal cancer: From heterogeneity to convergent evolution. Cancer Discovery, 4(11), 1269.

Misale, S., Yaeger, R., Hobor, S., Scala, E., Janakiraman, M., Liska, D., et al. (2012). Emergence of KRAS mutations and acquired resistance to anti-EGFR therapy in colorectal cancer. Nature, 486(7404), 532-536.

Moran, D. M., Trusk, P. B., Pry, K., Paz, K., Sidransky, D., \& Bacus, S. S. (2014). KRAS mutation status is associated with enhanced dependency on folate metabolism pathways in non-small cell lung cancer cells. Molecular Cancer Therapeutics, 13(6), $1611-1624$.

Owen, O. E., Kalhan, S. C., \& Hanson, R. W. (2002). The key role of anaplerosis and cataplerosis for citric acid cycle function. Journal of Biological Chemistry, 277(34), 30409-30412.

Papadopoulou, C., Guilbaud, G., Schiavone, D., \& Sale, J. E. (2015). Nucleotide pool depletion induces G-Quadruplex-dependent perturbation of gene expression. Cell Reports, 13(11), 2491-2503.

Phipps, A. I., Buchanan, D. D., Makar, K. W., Win, A. K., Baron, J. A., Lindor, N. M., et al. (2013). KRAS-mutation status in relation to colorectal cancer survival: The joint impact of correlated tumour markers. British Journal of Cancer, 108(8), 1757-1764.

Sanderson, S. M., Gao, X., Dai, Z. W., \& Locasale, J. W. (2019a). Methionine metabolism in health and cancer: A nexus of diet and precision medicine. Nature Reviews Cancer, 19(11), 625-637.

Sanderson, S. M., Mikhael, P. G., Ramesh, V., Dai, Z. W., \& Locasale, J. W. (2019b). Nutrient availability shapes methionine metabolism in p16/MTAP-deleted cells. Sci Adv, 5(6), 7769.

Seekhuntod, S., Thavarungkul, P., \& Chaichanawongsaroj, N. (2016). Validation of a multiplex allele-specific polymerase chain reaction assay for detection of KRAS gene mutations in formalin-fixed, 
paraffin-embedded tissues from colorectal cancer patients. PLoS ONE, 11(1), e0147672.

Seton-Rogers, S. (2019). KRAS-G12C in the crosshairs. Nature Reviews, 20, 3.

Son, J., Lyssiotis, C. A., Ying, H., Wang, X., Hua, S., Ligorio, M., et al. (2013). Glutamine supports pancreatic cancer growth through a KRAS-regulated metabolic pathway. Nature, 496(7443), 101.

Stolze, B., Reinhart, S., Bulllinger, L., Fröhling, S., \& Scholl, C. (2015). Comparative analysis of KRAS codon 12, 13, 18, 61, and 117 mutations using human MCF10A isogenic cell lines. Scientific Reports, 5, 8535.

Sumner, L. W., Amberg, A., Barrett, D., Beale, M. H., Beger, R., Daykin, C. A., et al. (2007). Proposed minimum reporting standards for chemical analysis. Metabolomics, 3(3), 211-221.

Tan, C., \& Du, X. (2012). KRAS mutation testing in metastatic colorectal cancer. World Journal of Gastroenterology, 18(37), $5171-5180$.

Tougeron, D., Lecomte, T., Pages, J. C., Villalva, C., Collin, C., Ferru, A., et al. (2013). Effect of low-frequency KRAS mutations on the response to anti-EGFR therapy in metastatic colorectal cancer. Annals of Oncology, 24(5), 1267-1273.

Tripathi, P., Kamarajan, P., Somashekar, B. S., MacKinnon, N., Chinnaiyan, A. M., Kapila, Y. L., et al. (2012). Delineating metabolic signatures of head and neck squamous cell carcinoma: Phospholipase A2, a potential therapeutic target. The International Journal of Biochemistry \& Cell Biology, 44(11), 1852-1861.

Tural, D., Selcukbiricik, F., Erdamar, S., Ozkurt, C. U., Yanmaz, T., Mandel, N. M., et al. (2013). Association KRAS G13D tumor mutated outcome in patients with chemotherapy refractory metastatic colorectal cancer treated with cetuximab. Hepato-Gastroenterology, 60(125), 1035-1040.

Vander Heiden, M. G., Cantley, L. C., \& Thompson, C. B. (2009). Understanding the Warburg effect: The metabolic requirements of cell proliferation. Science, 324, 1029-1034.

Varshavi, D., Scott, F. H., Varshavi, D., Veeravalli, S., Phillips, I. R., Veselkov, K., et al. (2018). Metabolic biomarkers of ageing in C57BL/6J wild-type and flavin-containing monooxygenase 5 (FMO5)-knockout mice. Frontiers in Molecular Biosciences, 5, 28.

Vartanian, S., Bentley, C., Brauer, M. J., Li, L., Shirasawa, S., Sasazuki, T., et al. (2013). Identification of Mutant K-Ras-dependent phenotypes using a panel of isogenic cell lines. Journal of Biological Chemistry, 288(4), 2403-2413.

Vazquez, A., Kamphorst, J. J., Markert, E. K., Schug, Z. T., Tardito, S., \& Gottlieb, E. (2016). Cancer metabolism at a glance. Journal of Cell Science, 129(18), 3367.
Veselkov, K. A., Mirnezami, R., Strittmatter, N., Goldin, R. D., Kinross, J., Speller, A. V. M., et al. (2014). Chemo-informatic strategy for imaging mass spectrometry-based hyperspectral profiling of lipid signatures in colorectal cancer. Proceedings of the National Academy of Sciences, 111(3), 1216-1221.

Veselkov, K. A., Vingara, L. K., Masson, P., Robinette, S. L., Want, E., Li, J. V., et al. (2011). Optimized preprocessing of ultraperformance liquid chromatography/mass spectrometry urinary metabolic profiles for improved information recovery. Analytical Chemistry, 83(15), 5864-5872.

Vizan, P., Boros, L. G., Figueras, A., Capella, G., Mangues, R., \& Bassilian, S. (2005). K-ras codon-specific mutations produce distinctive metabolic phenotypes in NIH3T3 mice [corrected] fibroblasts. Cancer Research, 65, 5512-5515.

Warburg, O. (1956). On the origin of cancer cells. Science, 123(3191), 309-314.

Wishart, D. S., Tzur, D., Knox, C., Eisner, R., Guo, A. C., Young, N., et al. (2007). HMDB: The human metabolome database. Nucleic Acids Research, 35, D521-D526.

Wong, C. C., Qian, Y., \& Yu, J. (2017). Interplay between epigenetics and metabolism in oncogenesis: Mechanisms and therapeutic approaches. Oncogene, 36(24), 3359-3374.

Yi, W., Clark, P. M., Mason, D. E., Keenan, M. C., Hill, C., Goddard, W. A., 3rd, et al. (2012). Phosphofructokinase 1 glycosylation regulates cell growth and metabolism. Science, 337(6097), 975-980.

Ying, H., Kimmelman, A. C., Lyssiotis, C. A., Hua, S., Chu, G. C., Fletcher-Sananikone, E., et al. (2012). Oncogenic Kras maintains pancreatic tumors through regulation of anabolic glucose metabolism. Cell, 149(3), 656-670.

Yokota, T. (2012). Are KRAS/BRAF mutations potent prognostic and/or predictive biomarkers in colorectal cancers? Anti-Cancer Agents in Medicinal Chemistry, 12(2), 163-171.

Yun, J., Rago, C., Cheong, I., Pagliarini, R., Angenendt, P., Rajagopalan, H., et al. (2009). Glucose deprivation contributes to the development of KRAS pathway mutations in tumor cells. Science, 325(5947), 1555-1559.

Publisher's Note Springer Nature remains neutral with regard to jurisdictional claims in published maps and institutional affiliations. 